\title{
Willingness To Pay Petani Lada Di Provinsi Lampung
}

\section{Willingness To Pay Of Pepper Farmers In Lampung}

\author{
Nuni Anggraini ${ }^{1 *}$, Dayang Berliana ${ }^{1}$, Bambang Utoyo $^{3}$ \\ ${ }^{1}$ Jurusan Ekonomi dan Bisnis Politeknik Negeri Lampung \\ ${ }^{3}$ Jurusan Produksi Manajemen Industri Perkebunan Politeknik Negeri Lampung \\ *E-Mail: nunianggraini@ polinela.ac.id
}

\begin{abstract}
Plantation commodities that play an important role in export and import activities were pepper. Based on Badan Pusat Statistik (2017), Indonesia the main supplier of black pepper to the United States market with a delivery rate of 20,423 metric tons (47\%). Means that Indonesia's opportunities enormous in pepper trade and business. One of the obstacles encountered by pepper farmers difficulty in getting quality pepper seeds. The expensive price of pepper seeds was one of the factors in the difficulty of getting high-quality and highquality plant material (Sutarman 2015). After selling the quality pepper seeds, an analysis of market response was needed, both in terms of market acceptance of these quality pepper seeds, as well as price responses from the pepper farmers themselves. This study aims to analyze the willingness of pepper farmers to pay for certified pepper seeds. This research was conducted in Way Kanan and North Lampung, which the centers of pepper production in Lampung. The number of respondents which was taken as a sample of 30 respondents. The used approached was a qualitative approach. Data collection techniques were direct observation (observation), in-depth interviews, questionnaires, and literature and documentation studies. The results showed that the value of the Willingness to Pay of consumer farmers was generally higher than the actual price, which was Rp 18,977.78. Variables that have a positive effect on WTP were age, marital status and income while the negative effects was the number of family members.
\end{abstract}

Keywords: pepper, seeds, VCM, Willingness to pay,

Disubmit : 2 Agustus 2019, Diterima: 29 Agustus 2019, Disetujui :17 Oktober 2019

\section{PENDAHULUAN}

Komoditas perkebunan yang berperan penting dalam kegiatan ekspor dan impor adalah lada. Lada merupakan salah satu tanaman rempah-rempah yang berperan penting dalam peningkatan perekonomian Indonesia (Martin, et al, 2015). Berdasarkan data dari Badan Pengawas Perdagangan Berjangka Komoditi tahun 2017, Indonesia adalah pemasok utama lada hitam ke pasar Amerika Serikat dengan tingkat pengiriman 20.423 metrik ton (47\%), diikuti oleh Brasil 8.715 metrik ton (20\%), Vietnam 7.963 metrik ton (18\%) dan India 5.600 metrik ton (13\%). Hal ini berarti peluang Indonesia sangat besar dalam perdagangan dan bisnis lada. Budidaya lada di Indonesia dilakukan dalam skala kecil hingga besar (Rukmana R, 2003). Salah satu daerah sentra lada di Indonesia adalah Provinsi Lampung. Menurut data dari (Badan Pusat Statistik, 2017) persentase produksi lada perkebunan rakyat (PR) di Provinsi Lampung adalah sebesar 26,08\% dari seluruh total produksi lada di Indonesia. Oleh karena itu, lada sering dijadikan lambang untuk menggambarkan daerah Provinsi Lampung. Walaupun sektor perkebunan memiliki peran cukup besar dalam 
perekonomian Negara sebagai sumber devisa dan memberikan kontribusi dalam PDRB, perkembangan perkebunan lada rakyat di Indonesia khususnya di Provinsi Lampung sebaliknya cenderung semakin menurun. Hal ini bertolak belakang dengan banyaknya permintaan ladadi dunia yang harus dipenuhi.

Salah satu daerah sentra produksi tanaman lada di Provinsi Lampung adalah Kabupaten Way Kanan. Kabupaten Way Kanan menempati urutan ke dua sebagai sentra produksi tanaman lada setelah Kabupaten Lampung Utara. Salah satu kendala yang ditemui oleh petani lada adalah sulitnya memperoleh bibit lada yang berkualitas. Harga bibit lada yang mahal merupakan salah satu faktor sulitnya mendapatkan bahan tanaman dalam jumlah banyak dan berkualitas (Utoyo et al., 2018). Belum adanya penangkar bibit lada di Lampung adalah salah satu kendala banyaknya bibit-bibit lada yang ditanam oleh petani yang tidak jelas asal induknya (illegitim). Produktivitas kebun lada rakyat di Lampung masih tergolong rendah yaitu rata-rata $591 \mathrm{~kg} / \mathrm{ha}$, dibandingkan dengan produktivitas nasional yang mencapai $800 \mathrm{~kg} / \mathrm{ha}$.

Melihat kendala yang dihadapi oleh petani yang akan berkebun lada untuk mendapatkan bibit yang berkualitas, Politeknik Negeri Lampung mencoba membantu petani yaitu dengan membentuk Unit Penangkar Bibit Lada Berkualitas. Penggunaan teknologi oleh unit penangkar bibit lada berkualitas antara lain menggunakan bibit varietas unggul yang bersertifikasi dan penggunaan agen hayati Trichoderma. Hasil penelitian yang dilakukan oleh (Manohara et al, 2005) menunjukkan cendawan Trichoderma harzianum mampu menekan intensitas serangan P.infestans (penyebab penyakit busuk pangkal batang lada) sebesar $50 \%$.

Setelah dilakukan penjualan bibit lada berkualitas ini, diperlukan analisis respon pasar terkait harga dari petani lada itu sendiri. Hal ini dapat menunjang pengembangan Unit Penangkar Bibit Lada Politeknik Negeri Lampung, apakah petani dapat menerima bibit lada yang dibudidaya dan bersedia untuk membayar bibit lada tersebut. Berdasarkan latar belakang dan perumusan masalah yang telah dikemukakan, tujuan dari penelitian ini adalah menganalisis kesediaan petani lada membayar bibit lada bersertifikat.

\section{METODE PENELITIAN}

\section{Tempat dan Waktu Penelitian}

Penelitian ini dilaksanakan diKabupaten Way Kanan dan Kabupaten Lampung Utara yang merupakan sentra penghasil lada di Provinsi Lampung. Waktu penelitian dilakukan pada Bulan Maret - Juni 2019.

\section{Metode Analisis Data}

Jumlah responden yang diambil sebagai sampel sebanyak 30 orang responden, dimana terdiri dari 15 petani lada yang berasal dari Kabupaten Way Kanan dan 15 petani lada yang berasal dari Kabupaten Lampung Utara. Analisis secara deskriptif dilakukan untuk menjelaskan gambaran umum usahatani lada dan analisis kesediaan untuk membayar pada perspektif petani lada. Prosedur dan analisis data yang digunakan adalah analisis deskripstif, dan CVM (Contingent Valuation Method). Tahap-tahap dalam melakukan penelitian untuk menentukan WTA/WTP dengann menggunakan CVM (Contingent Valution Method) meliputi (Fauzi A, 2004) yaitu :

1. Membuat Hipotesis Pasar

Pada awal proses kegiatan CVM, biasanya harus terlebih dahulu membuat hipotesis pasar terhadap sumberdaya yang akan dievaluasi, Dalam hal ini, hal yang perlu dilakukan adalah membuat suatu kuesioner yang berisi informasi lengkap mengenai kompensasi petani untuk melaksanakan, hal apa yang harus dilakukan untuk mendapatkan kompensasi yang layak, serta menentukan besarnya dana yang diinginkan oleh petani melalui kompensasi. Selain itu jika dilihat kondisi yang terjadi, dimana bibit lada telahter sertifikasi, maka konsumen dapat membayar lebih mahal.

2. Memperoleh Nilai Lelang (Bids) 
Nilai lelang dilakukan dengan melakukan survei. Tujuan dari survei ini untuk memperoleh nilai maksimum keinginan membayar (WTP) dari responden.

3. Menghitung Rataan WTP

Perhitungan ini biasanya didasarkan pada nilai mean (rataan) dan nilai median (tengah). Selanjutnya dugaan rataanWTP dihitung dengan rumus (Jordan\& Elnagheeb (1993) dalam (Nyanyu, 1999):

$$
\mathrm{EWTP}=\sum_{i=1}^{n} W_{i} P F t
$$

Keterangan:

$\begin{array}{ll}\text { EWTP } & \text { =dugaanrataan WTP } \\ \text { Wi } & =\text { batas bawah kelas WTA kelas ke-i } \\ \text { Pfi } & =\text { frekuensi relatif kelasyangbersangkutan } \\ \mathrm{n} & \text { =jumlah kelas (interval) } \\ \mathrm{i} & \text { =kelas (interval) WTP; } \mathrm{i}=1,2,3\end{array}$

4. Menentukan Total WTA/WTP

Total WTP dapat digunakan untuk menduga WTP populasi secara keseluruhan dengan rumus (Pearcedan Turner (1989) dalam ( Nyayu, 1999)

$$
\text { TWTP }=\sum_{i=1}^{n} \frac{n}{N} P
$$

Keterangan:

TWTP =kesediaanpetani untukmembayar

WTP i =kesediaan responden (sampel)untuk membayar

$\mathrm{n} \quad \quad=$ jumlah luas lahan sampel petani yang bersedia menerima

$\mathrm{N} \quad=$ jumlah luas lahan sampelpetani

$\mathrm{P} \quad \quad=$ jumlah luas lahan populasi petani

i $\quad$ =sampel; $i=1,2, \ldots$

Untuk mengetahui faktor-faktor yang mempengaruhi WTPpetani terhadap penggunaan bibit lada bersertifikat digunakan model regresi berganda. Maka persamaan regresi dalam penelitian ini adalah sebagai berikut:

$$
\mathrm{WTP}=\mathrm{b}_{0}+\mathrm{b}_{1} \mathrm{X}_{1}+\mathrm{b}_{2} \mathrm{X}_{2}+\mathrm{b}_{3} \mathrm{X}_{3}+\mathrm{b}_{4} \mathrm{X}_{4}+\mathrm{e}
$$

Keterangan:

$\mathrm{WTP}=$ nilai harga kesediaan membayar

$\mathrm{X} 1=$ usia petani (tahun)

$\mathrm{X} 2=$ Status pernikahan (dummy $1=$ menikah, $0=$ belum menikah)

$\mathrm{X} 3 \quad=$ pendapatan $(\mathrm{Rp})$

$\mathrm{X} 4 \quad$ = jumlah anggota keluarga (orang)

\section{HASIL DAN PEMBAHASAN}

\section{Karakteristik Petani Responden}

Umur responden sangat bervariatif. Hasil sebaran menunjukkan meyoritas reponden meiliki usia antara 20-35 tahun sebanyak 50 persen (12 orang). Petani yang berumur relatif lebih muda mempunyai fisik lebih baik dari pada petani yang lebih tua dan lebih berani menanggung risiko akan tetapi petani yang lebih muda biasanya masih kurang memiliki pengalaman. Untuk mengimbangi kekurangan ini petani lebih muda 
lebih dinmis untuk mengadopsi inovasi baru tangap terhadap perubahan yang terjadi, sehingga cepat mendapat pengalaman (Liana 2013).

Dari segi tingkat pendidikan diukur berdasarkan tingkat pendidikan formal yang pernah diikut.Data menunjukkan bahwa petani rata-rata berpendidikan SD, SMP dan SMA.Hal ini terlihat pada presentase reponden masing-masing 58 persen, 31 persen dan 11 persen. Kemampuan petani sebagaipengelola erat hubungannya dengan pendidikan formal petani, dimana tingkat pendidikan merupakan salah satu faktor yang memperngaruhi cara berpikir dan daya nalar terhadap penyerapan ilmu pengetahuan dan teknologi. Semakin tinggi tingkat pendidikan petani, maka dapat semakin luas wawasannya dalam mengambil keputusan untuk menggunakan biibit lada bersertifikat.

Jumlah anggota keluarga diukur beradasarkan jumlah angkatan kerja dalam keluarga dan jumlah anak yang masih bersekolah. Jumlah anggota keluarga yang menjadi tanggungan responden berkisar antara 1-5 orang dengan rata-rata 3 orang.Mayoritas responden meiliki tanggungan keluarga $\leq 3$ orang sejumlah 54 persen yakni sebanyak 14 orang. Banyaknya jumlah anggota yang ditanggung petani akan menyebabkan semakin banyak pengeluaran rumah tangga petani. Dengan semakin banyaknya jumlah anggota keluarga maka makin banyak pula yang membantu melakukan kegiatan usahatani yang dilakukan sehingga dapat menekan biaya pengeluaran yaitu biaya tenaga kerja (Mulyana, 2017).

\section{Analisis Willingness to Pay}

Metode yang digunakan untuk mengetahui jumlah minimum yang bersedia diterima oleh petani adalah metode Contingen Valuation Method (CVM).Harga aktual bibit lada bersertifikat yang dibeli oleh petani sebesar Rp 12.000. Hasil penelitian menunjukkan bahwa 30 responden bersedia untuk membayar. Nilai minimum WTP petani lada sebesar Rp 15.000, nilai maksimum WTP petani lada sebesar Rp 21.500 dengan rata-rata nilai WTP petani lada untuk setiap batangnya adalah sebesar Rp 18.173 dan dapat dilihat pada Gambar 1.

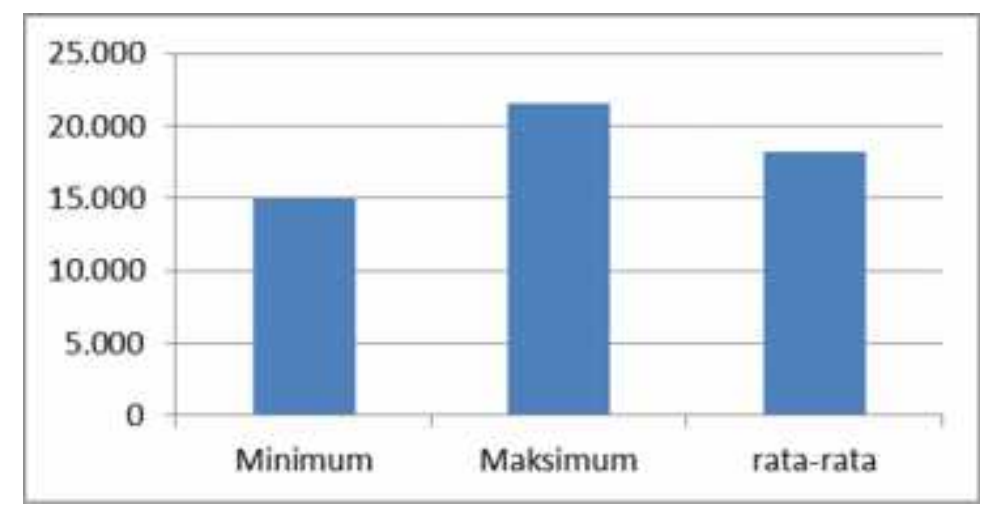

Gambar 1. Sebaran Nilai WTP Petani Lada

Kesediaan petani lada untuk membayar bibit lada bersertifikat adalah sebesar Rp 18.173, nilai tersebut masih lebih tinggi apabila dibandingkan dengan nilai aktual bibit lada yaitu sebesar Rp 12.000. Hal ini 


\section{Journal of Food System and Agribusiness}

menunjukkan bahwa apabila terjadi kenaikan harga pada bibit lada bersertifikat petani masih bersedia untuk membayar bibit lada bersertifikat sampai dengan nilai maksimumnya sebesar Rp 21.000. Kesediaan petani untuk membayar bibit lada bersertifikat dengan harga yang lebih tinggi dibandingkan harga aktual adalah sesuai dengan produksi lada yang diperoleh lebih tinggi ketika menggunakan bibit lada bersertifikat. Dimana produktivitas kebun lada rakyat di Lampung masih tergolong rendah yaitu rata-rata $591 \mathrm{~kg} / \mathrm{ha}$ dibandingkan dengan produktivitas nasional yang mencapai $800 \mathrm{~kg} / \mathrm{ha}$.

\section{Faktor yang Mempengaruhi Kesediaan Membayar Petani}

Analisis yang digunakan untuk menjelaskan hubungan antara variabel respon atau variabel dependen. Ada empat variabel bebas yang terdiri dari usia petani, status pernikahan, pendapatan dan jumlah anggota keluarga sedangkan variabel dependennya adalah nilai WTP responden.

Tabel 1. Faktor-faktor yang mempengaruhi kesediaan membayar petani terhadap bibit lada bersertifikat

\begin{tabular}{lccc}
\hline Variabel Bebas & Koefisien & Sig & VIF \\
\hline Constant & 14887.457 & 0.049 & \\
Usia & 68.733 & 0.034 & 1.284 \\
Status Pernikahan & 374.133 & 0.671 & 1.798 \\
Pendapatan & 0.002 & 0.016 & 1.089 \\
Jumlah Anggota & -4.223 & 0.226 & 1.345 \\
Keluarga & & & \\
\hline RSquare & 0,571 & & \\
Adjusted $R$ Square & 0,539 & & \\
\hline
\end{tabular}

Sumber : Data Primer (diolah)

Berdasarkan uji asumsi terhadap multikolinieritas, autocorrelation, homoskedastisitas menujukkan bahwa model regresi yang dilakukan memenuhi asumsi. Pemenuhan asumsi-asumsi menandakan bahwa model regresi ini layak digunakan.Model yang dihasilkan pada metode ini adalah :

$$
\mathrm{WTP}=14887.457+68.733 \mathrm{U}+374.133 \mathrm{SP}+0.002 \mathrm{PENDT}-4.223 \mathrm{JAK}+\mathrm{e}
$$

Variabel usia petani memiliki signifikansi 0.034 . Koefisien tanda positif dengan nilai bertanda positif (+) dengan nilai sebesar 68.733. Artinya jika usia meningkat satu satuan (tahun), maka nilai WTP yang diberikan akan meningkat sebesar 68.733. Variabel usia dapat menjelaskan bahwa usia seseorang akan menunjukkan kematangan psikologis dirinya sehingga akan mempenharuhi proses pengambilan keputusan dalam hidupnya. Terkait dengan pengambilan keputusan khususunya pembelian bibit lada bersertifikat, oleh karena itu dapat disimpulkan kesediaan untuk membeli bibit lada bersertifikat sebagian besar tersebar pada responden yang berusia 29-39 tahun.

Variabel status pernikahan memiliki signifikansi 0.036.Koefisien tanda positif dengan nilai bertanda positif (+) dengan nilai sebesar 374.133.Kategori responden yang bersedia membayar didominasi oleh responden yang berstatus menikah daripada yang masih lajang.Keseragaman ini yang menyebabkan variabel tidak berpengaruh terhadap model.

Variabel pendapatan memiliki koefisien 0.02.Koefisien tanda positif dengan nilai bertanda positif $(+)$ dengan nilai sebesar 0.02. Artinya jika usia meningkat satu satuan (rupiah), maka nilai WTP yang diberikan akan meningkat sebesar Rp 0.02. Tingkat pendapatan sangat mempengaruhi pola hidup seseorang karena pendapatan menujukkan tingkat kesejahteraan pola hidup seseorang.

Variabel Jumlah Anggota Keluarga memiliki nilai koefisien sebesar 4.223 koefisien tanda negatif dengan nilai sebesar 4.223, maka nilai WTP yang akan diberikan akan menurun sebesar satu satuan (rupiah) 
Rp 4.223. Jumlah tanggungan mencerminkan jumlah pengeluaran rumah tangga akan kebutuhan sehari-hari. Jumlah tanggungan diduga tidak berpengaruh nyata karena berdasarkan survey jumlah pengeluaran rumah tangga yang memiliki tanggungan lebih banyak tidak jauh berbeda dengan jumlah pengeluaran rumah tangga yang memiliki jumlah tanggungan sendikit.Hal ini yang menyebabkan tidak berpengaruh nyata terhadap model.

\section{KESIMPULAN}

Berdasarkan hasil penelitian maka kesimpulan yang diperoleh adalahnilai Willingness to Paypetani konsumen secara umum lebih tinggi dibandingkan dengan harga aktual, yaitu Rp 18.173.Variabel yang berpengaruh positif terhadap WTP konsumen antara lain, usia, status pernikahan, dan pendapatan sedangkan yang berpengaruh negatif adalah variabel jumlah anggota keluarga.

\section{DAFTAR PUSTAKA}

Badan Pusat Statistik (2017) Lampung Dalam Angka. Bandar Lampung.

Fauzi A (2004) Ekonomi Sumberdaya Alam dan Lingkungan Teori dan Aplikasi. Jakarta: PT Gramedia Pustaka Utama.

Manohara, D., Wahyuno, D., and Noveriza, R. (2005) 'Penyakit busuk pangkal batang tanaman lada dan strategi pengendaliannya', Perkembangan Teknologi Tanaman Rempah dan Obat, 17(2), pp. 41-57.

Martin, A. B., Same, M. and Indrawati, W. (no date) 'Pengaruh Media Pembibitan pada Pertumbuhan Setek Lada ( Piper nigrum L .) ( Influence of Growing Medium on the Growth of Pepper [ Piper nigrum L .] Cutting Seedlings )’, 3(2), pp. 94-107.

Mulyana, E., Purbiyanti, E. and Januarti, I. (2017) 'Analisis Pendapatan Petani Nanas di Desa Tanjung Atap Kecamatan Tanjung Batu Kabupaten Ogan Ilir. Journal of Food and System Agribusiness. 1(2), pp. 78-83.

Nyayu Neti Arianti (1999) Analisis Pilihan Sumber Air Bersih dan Kesediaan Membayar bagi Perbaikan Kualitas dan Kuantitas Air PDAM di Kodya Bengkulu. Institut Pertanian Bogor.

Rukmana R (2003) Usaha Tani Lada Perdu. Yogyakarta: Kanisius.

Utoyo, B. et al. (2018) 'Pengembangan Unit Penangkar Bibit Lada Berkualitas Di Politeknik Negeri Lampung', 3(2), pp. 96-100. 